\title{
TK 156.437
}

KFKI

$20 / 196 \$$

1967

\section{CORRELATION TYPE TIME-OF-FLIGHT SPECTROMETER WITH MAGNETICALLY PULSED POLAFIZED NEUTRONS}

J. Gordon, N. Kroó, G. Orbán, L. Pál,

P. Peilionisz, F. Szlávik, I. Vizi

HUNGARIAN ACADEMY OF SCIENCES

CENTRAL RESEARCH INSTITUTE FOR PHYSICS 


\title{
CORREIATTION TYPE TIME-OF-FLIGHT SPECTROMEITER
} WITH MAGNETICALLY PULSED POLARIZED NEUTRONS

\author{
J. Gordon, N. Krob, G. Orbán, I. Pál \\ J. Pellionisz, F. Szlávik, I.Vizi \\ Central Research Institute for Physics, \\ Budapest.
}

1

Abstract

Correlation type time-of-flight spectrometer has been built for inelastic neutron scattering measurements. The main features of the experimental set-up and the first test runs are described. 
The time-of-flight method is frequently used in inelastic neutron scattering experiments. The main disadvantage of this method is its poor neutron economy, limited time resolution and the presence of the fast neutron background, not to speak of the maintenance problems and other limitations posed by the mechanical choppers.

In this communication an experiment is presented which partly eliminates these shortcomings. The set-up makes use of the so called correlation technique $[1,2]$. According to this, the transfer function $h(\tau)$ of a system which is the conventional time-of-flight distribution function is proportional to the cross-correlation function

$$
C_{x y}(\tau)=\lim _{\tau \rightarrow \infty} \frac{1}{T} \int_{0}^{T} x(t) y(t-\tau) d t
$$

where $\mathrm{x} / \mathrm{t} / \mathrm{is}$ a random signal with $\delta$-function type auto-correlation function and $\mathrm{y} / \mathrm{t} / \mathrm{is}$ the response of the system to $\mathrm{x} / \mathrm{t} /$. The random signal has to be replaced in practice by a pseudo-random sequence with a sufficiently long repetition period. In this case the correlation function is well approximated by computing the integral for this period only.

The schem of the experiment can be seen in Fig.1. The monochromatic, polarized neutron beam, reflected by the first Co/8 \% Fe/ crystal is reflected in the same way by the second one if the spin-flipper between the crystals is switched off. It the flipper is "on" it reverses the neutron spins and the intensity after the second crystal is zero. If the oscillator of the flipper is controlled i.e. kept in "on" or "off" condition by a binary pseudo-random generator, the polarized neutron beam after the analyzer crystal is modulated in a pseudo-random way in time. Consequently, the auto-correlation function of this beam intensity is well approximated by a $\delta$-function.

This beam is scattored by the sample and detected in a few meters distance. The sample, the flight-path and the detector form the transfer system characterized by $h(\tau)$.

Pulses from the neutron detector are stored in the first half of the ferrite-core memory / first sector/, of a conventional multichannel analyzer. The addres-register of the analyzer receives the shift-pulses of the pseudo-random generator. The "word length" of the binary pseudo- 
-random sequence is equal to 256, half of the total channel number of the analyzer applied. When the number of counts in any channel attain a preset value, the "KORAII-A" correlator-plug-in unit stops the measurement and initiates the coputing poriod [3]. During this period the whole cross correlation function $C_{x y} / \tau /$ is computed in less than. 3 seconds and stored in the form of 256 discrete ordinate values in the second half / second sector/ of the memory. Data from any sector can be seen on a cathode-ray tube, punched or printed on paper tapes etc. During the computation period data in the first sector remain unchanged. Thus the measurement can be continued making use of the data accumulated previously.

In order to test the operation of the correlation spectrometer the time-of-flight spectrum of the monoenergetic, polarized beam was measured. This function i.e. the result of the computation process is shown in Fig.2. The figure displays clearly the $\delta$-function-like behaviour.

The main adventages of the correlation technique can be summed up as follows:

1./ The neutron economy of the spectrometer is better than that of the conventional ones, if the number of counts in a channel is high compared to the average value.

2./ Since there is no correlation between the background and the random modulation of the incident beam, the spectrometer can effectively work even at high background values.

3./ The magnetic chopper /chopped spin-flipper/ allowes the use of very good resolutions in time.

4./ The polerized beam makes the spectrometer especially useful for magnetic studies.

5./ Besides the monocrystals and the spin flipper only a commercial multichannel analyzer completed with a simple plug-in unit is necessary for the measurements and for the fast evaluation of the data obtained. 
1

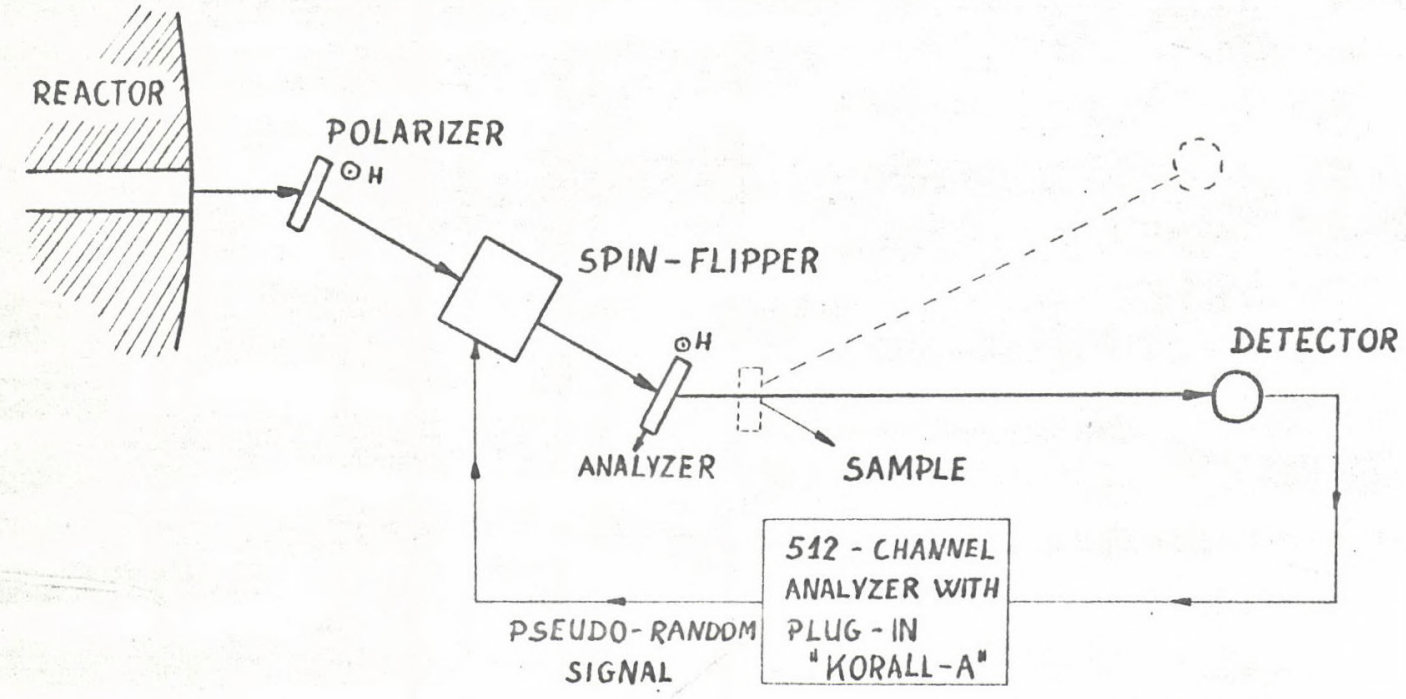

Fig. 1.

Scheme of the correlation spectrometer. 


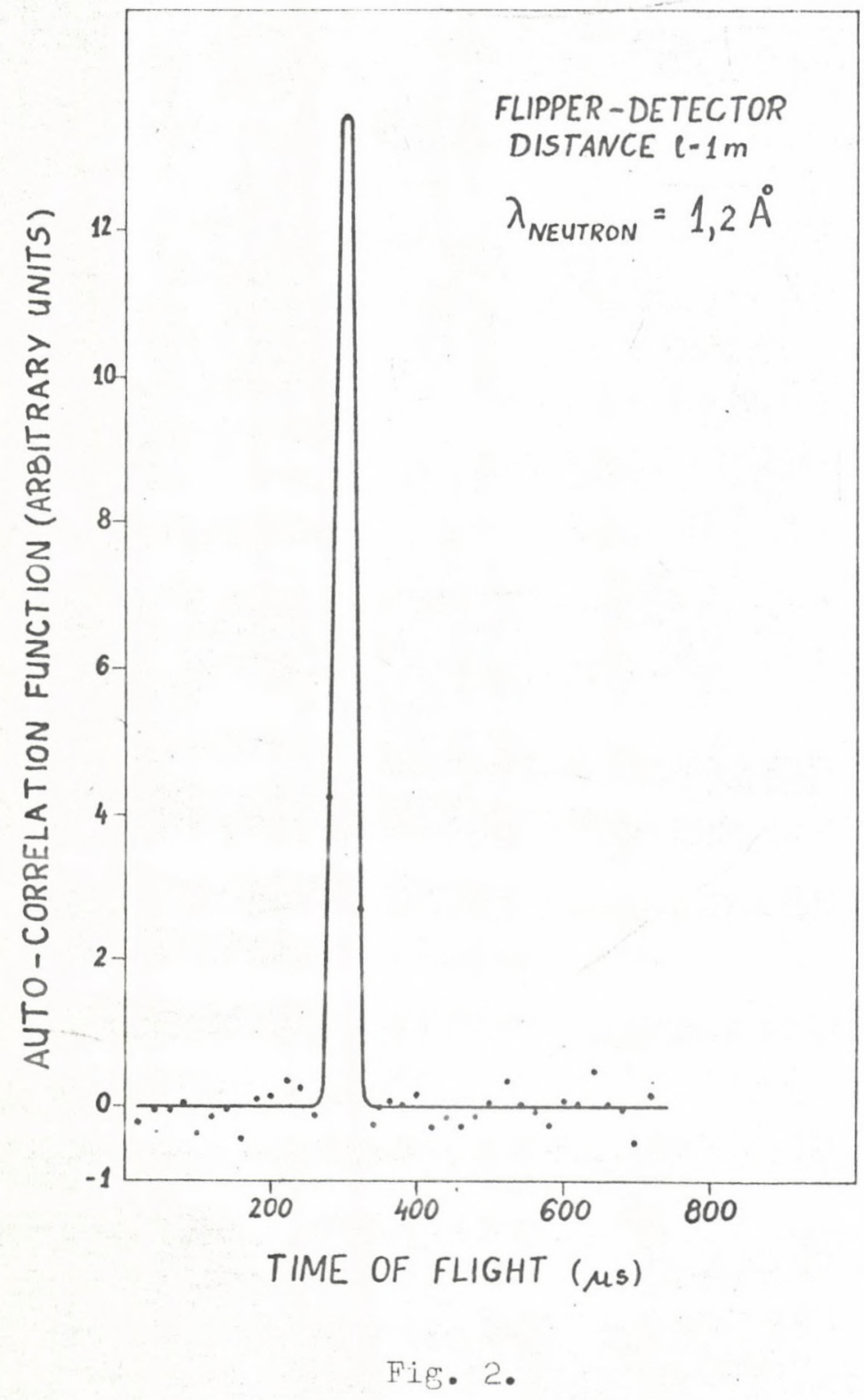

Auto-correlation function of the incident neutron beam measured on the detector. 


\section{References}

1 Mogilner A.I., Salnikov O.A., Timohin I.A.: Pribori 1 Technika Eksperimenta /March-Apri1. 1966./ in Russian.

2 Cooke-Yarborough E.H.: Instr. Techn. in Nucl. Pulse Analysis, Nat. Acad. of Sc1. Washington, 1964.

3 P. Pellionisz, F. Szlávik: Mérés és Automatika XV, 260, 1966. in Hungarian. 
65236 